\title{
Waardenburg Syndrome Type 1 in an Infant Diagnosed with Congenital Hypothyroidism
}

\section{Kavinda Chandimal Dayasiri ${ }^{1}$, Chamila Perera ${ }^{2}$, Wasana Bandara ${ }^{3}$ and Jagath Ranasinghe ${ }^{4}$}

${ }^{1}$ Department of Paediatrics, Base Hospital Mahaoya, Sri Lanka

${ }^{2}$ Department of Paediatrics, Teaching Hospital Kuliyapitiya, Sri Lanka

${ }^{3}$ Department of Paediatrics, Base Hospital Medirigiriya, Sri Lanka

${ }^{4}$ Department of Paediatrics, Great Ormond Street Hospital, United Kingdom

\section{Correspondence:}

Dr. Kavinda Chandimal Dayasiri

Department of Paediatrics,

Base Hospital Mahaoya,

Sri Lanka

E-mail: kavindadayasiri@gmail.com

DOI: $10.3126 /$ jnps.v39i1.20910

Submitted on: 2019-03-15

Accepted on: 2020-03-14

Acknowledgements: None

Funding: Nil

Conflict of Interest: None declared

Permission form IRB: Yes
To cite this article: Dayasiri $\mathrm{KC}$, Perera $\mathrm{C}$, Bandara $\mathrm{W}$ and Ranasinghe $\mathrm{J}$. Waardenburg Syndrome Type 1 in an infant diagnosed with congenital hypothyroidism. J Nepal Paediatr Soc. 2018;39(1):60-2.

\begin{abstract}
Waardenburg syndrome type 1 is a rare autosomal dominant auditory-pigmentary syndrome characterised by pigmentary abnormalities of the hair, skin, and eyes associated with congenital non-progressive sensorineural hearing loss. Diagnosis is usually clinical and based on the characteristic clinical features which constitute major and minor criteria. Though hypothyroidism has been described among family members of children with Waardenburg syndrome type 1 there is no reported existence of the two conditions in the same patient. Here we report Waardenburg Syndrome Type 1 in an infant who was already diagnosed to have congenital hypothyroidism and whether it would be a co incidental finding or an association needs further evaluation.
\end{abstract}

Key words: congenital hypothyroidism; infant; Waardenburg Syndrome Type 1

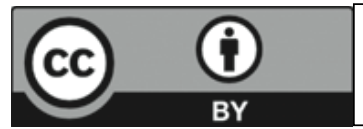

This work is licensed under creative common attribution 3.0 license 


\section{INTRODUCTION}

Waardenburg syndrome (WS) type 1 is characterised by hypopigmentation, premature graying of hair, synophrys, broad nasal root, dystopia canthorum, congenital sensory neural hearing loss, white forelock, and positive family history of WS. ${ }^{1}$ Phenotypic manifestations of WS type 1 are due to absence of melanocytes in the cochlear, skin, eyes and hair. WS type 1 is inherited in an autosomal dominant pattern and most cases are caused by mutations in PAX3 gene located on the long arm of chromosome $2 .{ }^{2}$ Diagnostic criteria for WS have been proposed by the Waardenburg Consortium in 1992.3 Presence of dystopia canthorum distinguishes WS type 1 from that of type 2.4

In this paper, we report an 11-month-old girl with WS1 who exhibited white forelock, cutaneous depigmented patches, dystopia canthorum, and flat broad nasal root with a positive family history of WS type 1 .

\section{CASE REPORT}

Eleven months old diagnosed child with congenital hypothyroidism presented to the paediatric casualty unit following an acute medical illness. She was born to non consanguineous parents with an uncomplicated birth history but congenital hypothyroidism was identified soon after birth. As she had been on thyroxin since birth she had attained developmental mile stones appropriate for her age. During physical examination child was found to have dystopia canthorum, white forlock on the anterior scalp, multiple cutaneous depigmented zones over trunk, and a broad, flat nasal root.

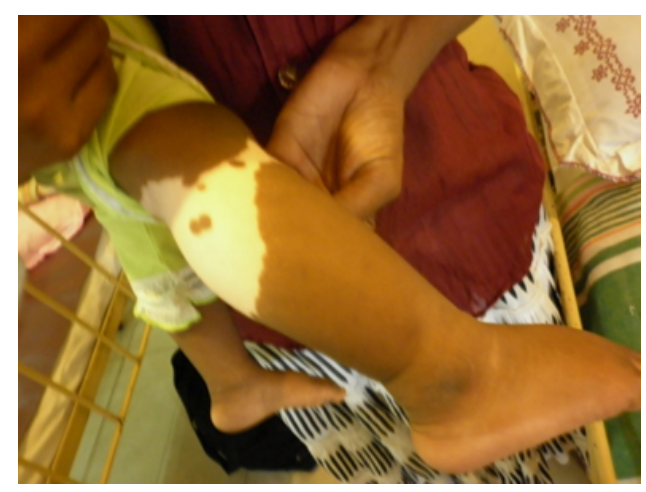

Figure 1. Cutaneous depigmented zone over right upper leg and popliteal region
Dystopia canthorum (W index - 2.01) was further confirmed by formal ophthalmological evaluation. On further assessment it was noted that her father as well as the paternal cousin had features sufficient to diagnose WS type 1.

\section{DISCUSSION}

Wardenburg syndrome is an autosomal dominant auditory pigmentary disorder that accounts for 3\% of congenitally deaf children with an estimated prevalence of $1: 20,000$ to $1: 40,000 . .^{5}$ Whilst differential diagnosis of WS type 1 includes other types of WS and other causes of congenital, nonprogressive sensory neuronal hearing loss, dystopia canthorum (W index > 1.95) clinically distinguishes WS type 1.

The underlying genetic mutation involves PAX3 in both WS types 1 and 3 whereas mutations in microphthalmia associated transcription factor gene are identified in WS type $2 .{ }^{6} \mathrm{PAX} 3$ is expressed in neural crest and WS type 1 is also considered to be a neurocristopathy. There have been reports of spina bifida and cleft palate among multiple families with WS type $1 .^{6}$ The diagnosis of Waardenburg syndrome necessitates presence of 2 major criteria or one major criterion in addition to two minor criteria. ${ }^{3,7}$

Major criteria include dystopia canthorum, white forlock, heterochromia irides, an autosomal dominant family pedigree and neurosensory cochlear deafness for at least two frequencies between $250-4000 \mathrm{~Hz}$. Minor criteria include cutaneous depigmented zones, synophrys, prominent and flat nasal root, hypoplastic alae nasi, premature greying of the hair. Rare signs that have

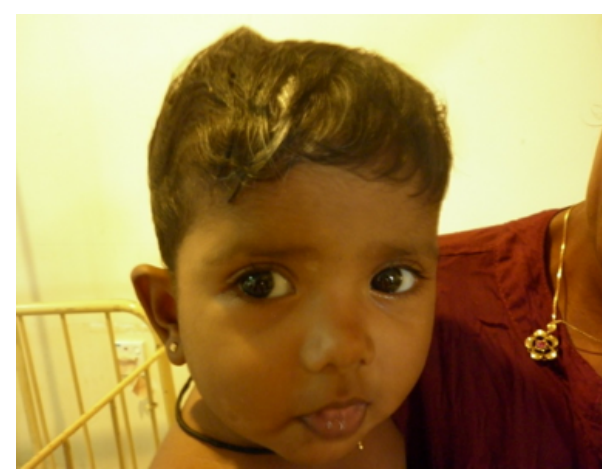

Figure 2. Objectively demonstrated dystopia canthorum, white forlock and prominent flat nasal root 
been described in WS type 1 include sprengel deformity, spina bifida, congenital heart disease, abnormal vestibular function, cleft lip and palate. ${ }^{7}$ The child reported in this paper fulfilled 3 out of 4 major criteria and 2 out of 5 minor criteria.

Management of WS type 1 includes audiological evaluation and consultation with clinical geneticist. Cochlear implantation has been performed successfully in children with WS type 1 to improve hearing. ${ }^{8}$ It is also important to offer family screening for at risk relatives by audiological evaluation, physical examination and where a known pathogenic mutation is present, by molecular genetic testing. Given the possible association of WS type 1 with neural tube defects, folic acid supplementation is recommended during pregnancy of affected individuals. ${ }^{9}$

Hypothyroidism has been reported among family members of children affected with WS type $1^{10}$, however, congenital hypothyroidism has not been reported in the same child who has been diagnosed with WS type 1 . Recent case reports suggest that intellectual impairment and behavioural abnormalities may be associated with WS type $3 .^{10}$
In our child whether congenital hypothyroidism would be a coincidence or an association needs further evaluation. If it is found to have association this would be the first case to report of congenital hypothyroidism associated with Waardenburg syndrome type 1 .

\section{CONCLUSIONS}

This case report presents a child in whom the diagnosis of Waardenburg syndrome type 1 was confirmed based on clinical findings. Early diagnosis enables early rehabilitation of hearing impairment, genetic counselling and family screening. Although hypothyroidism has been reported among family members of children with WS type 1, congenital hypothyroidism has not been reported in affected children. Whether this observation would be a co incidental finding or an association needs further evaluation.

\section{REFERENCES}

1. Waardenburg P. A new syndrome combining developmental abnormalities of the eye, eye brows and nose root, with pigmentary defects of the iris, head, hair and congenital deafness. Am J Hum Genet. 1951;3:195-253.

2. Badner JA, Chakra varti A. Waardenburg syndrome and Hirschsprung disease: Evidence for pleiotropic effect of a single dominant gene. Am J Med Genet. 1990;35:100-4. DOI: 10.1002/ajmg.1320350119

3. Farrer LA, Grundfast KM, Amos J, Arnos KS, Asher JH, Beighton P, et al. Waardenburg syndrome type I is caused by defects at multiple loci, one of which is near ALPP on chromosome 2: first report of the WS consortium. Am J Hum Genet. 1992;50:90213.

4. Pardono E, Van Bever Y, Van den Ende J, Havrenne PC, Iughetti P, Maestrelli SR, et al. Waardenburg syndrome: Clinical differentiation between type 1 and type 2. Am J Med Genet. 2003;117A:223-35. DOI: 10.1002/ajmg.a.10193

5. Tamayo ML, Gelvez N, Rodriguez M, Florez S, Varon C, Medina D, et al. Screening program for Waardenburg syndrome in Colombia: clinical definition and phenotypic variability. Am J Med Genet A. 2008;146A:1026-31. DOI: 10.1002/ajmg.a.32189

6. Karaman A, Aliagaoglu C.Waardenburg syndrome type 1. Dermatol Online J. 2006 Mar;12(3):21.

7. Faivre L, Vekemans M. Waardenburg syndrome type 1. Orphanet Encyclopedia. April 2005.

8. Amirsalari S, Ajallouyean M, Saburi A, Haddadi Fard A, Abed M, Ghazavi Y. Cochlear implantation outcomes in children with Waardenburg syndrome. Eur Arch Otorhinolaryngol. 2012;269:2179-83. DOI: 10.1007/s00405-011-1877-3

9. Fleming A, Copp AJ. Embryonic folate metabolism and mouse neural tube defects. Science. 1998 Jun 26;280(5372):2107-9. DOI: $10.1126 /$ science. 280.5372 .2107

10. Kiani R, Gangadharan SK, Miller H. Case report: Association of Waardenburg syndrome with intellectual disability, autistic spectrum disorder and unprovoked aggressive outbursts: A new behavioural phenotype? Br. J. Dev. Disabil. 2007;104: 53-62. DOI: doi.org/10.1179/096979507799103478 